\title{
Networks in local health systems: towards new spaces?
}

\author{
Sebastien Fleuret
}

(C) Springer Science+Business Media B.V. 2009

\begin{abstract}
New organizations of care and social service delivery (especially the development of coordination and networks) are leading to the definition new spaces. This article is based on examples of restructuring of health care systems in France and in Quebec. Both are moving towards more integration of delivery of care. In Quebec, 95 territories were created with a leading structure: the center for health and social services. This structure is responsible for bringing all the providers of services into a network and for giving to the population the guarantee of continuity and quality of care. It results in a new geography of health at the local scale. In France, continuity and quality of care are also used as arguments to justify changes in the organization of the system.
\end{abstract}

Keywords Health care $\cdot$ Networks .

Restructuring · Organizations

S. Fleuret

CNRS, UMR ESO, Université d'Angers, Angers, France

S. Fleuret $(\square)$

CARTA-ESO, Université d'Angers, 35 rue de la barre, 49000 Angers, France

e-mail: sebastien.fleuret@univ-angers.fr
The role of space in health care policy can be conceived as taking two forms. First and most obviously, there is a simple spatial division (...) secondly, measures such as community care, neighbourhood nursing and locality planning are embodying rather more subjective assumptions associated with function, role and meaning. (Moon 1990, p. 158)

\section{Introduction}

The importance of networks for health practices and the popularity of networks in recent health care restructuring processes have placed this topic on the health geography agenda. The purpose of this article is to point out that the new organizations of care and social service delivery, resulting from the development of networks, lead to the emergence of new spaces of health care.

Recent events in the evolution of health care systems in many developed countries have resulted in restructuring (or re-engineering), leading to the formation of networks and various forms of local health coordination. For example, in the need to provide care for activities of daily living (ADL), specialist medical care remains at the core of networks of providers but they are now joined by general practioners, social workers, volunteers and other actors who work together to provide home care for mainly elderly populations. Another example is 
that the search for efficiency and cost savings also leads to restructuring and mergers in the development of ambulatory care, with numerous spatial consequences (polarization, spatial inequities, etc.). According to Miller (2000, cited in Cartier 2003, p. 2295), "the economic organisation of health care services is a necessarily spatial set of processes with spatial results." Yet, restructuring in the health system has proceeded as if the location of services, and experiences of those living and working in specific places, have not mattered, or mattered primarily as a strategy of economic efficiency.

Thus, an important part of the literature on health networks is oriented towards the field of health services management (Ackerman 1992; Shortell and Hull 1996; Ferlie 1997; Bazzoli et al. 1999; Iles and Sutherland 2001). Some relevant references can also be found in the literature in French (e.g., Meyer and Coufinhal 1996; Contandriopoulos et al. 2001; Lamarche et al. 2001). Indeed, the literature generally deals with the way health systems have been restructured, and raises diverse issues like mergers (Weil 2000), organisational aspects (Robinson and Casalino 1996), the assessment of the efficiency of the integration of services (Conrad and Shortell 1996; Lesser et al. 2003; Nock 2004), partnerships (Jutras 1990) and chains of care (Ahgren and Axelsson 2007). Even if they are not the majority, some articles have adopted a geographic approach, and these have mostly featured case studies in the United States (e.g., Moscovice et al. 1997; Weil 2000), United Kingdom (e.g., Atkinson 1995; Fulop et al. 2005) or New Zealand (e.g., Kearns and Joseph 1997; Ashton et al. 2005). Only few researchers adopt a territorial approach that envisages the spatial consequences of restructuring (Smyth 2005).Yet, as suggested by Moon (1990), spaces and places are at the centre of the theoretical construction of health policies (implicitly even explicitly). In the same way, Eyles (1990) examined the significance of spatial configurations in health systems concluding that geography sheds light on the issues of economic development, policies structures and ideology.

According to the WHO, "from now the acute shortage of resources constrained countries to be opened to new solutions and new ways of thinking" (Dr. J.P. Jardel; WHO/OMS 1996, p. 1). This argument results in a recommendation to consider the integration of care at large, or in other terms, to think about "health" as a whole and "care" as an industry (Fleuret 2007). Indeed, networking, especially among public, private and voluntary sectors, often stands for "the solution to all problems, the paradigm of the twentieth century" (Bailly et al. 2006, p. 58). However, the development of health networks do not occur in the same ways and conditions vary in all Western countries. While a great majority of the literature on this topic is based on case studies in an Anglo-American context (see above) focusing mostly on two models: the American HMO and the British NHS, different models exist; however, these are not well known beyond their borders. ${ }^{1}$ Extending the range of case studies could bring out new understandings by introducing new concepts, ideologies and contexts (geographic and historic).

This paper aims to build understanding of such issues by researching the connections between spatial restructuring and integration processes that feature the development of health system networks. Its purpose is to point out that new organizations of care and social service delivery (restructuring), resulting in the development of networks, leads to the emergence of new spaces of health care. These new spaces should receive more consideration from policymakers who currently focus more on economic and organisational issues. Furthermore, if the networks are typically geographic subjects, the background of their development are under-studied despite the fact that they are of analytical interest to health geographers and health studies researchers. Therefore, the approach used in this research focuses on a comparative analysis of two specific spaces: France and Quebec ${ }^{2}$ (Canada). Similar to other Western health care systems, these jurisdictions faced extensive restructuring in the years between 1990 and 2000, and France and Quebec are comparable because they both have a strong commitment to offering public care and a universal health insurance system, and both are characterized by a strong

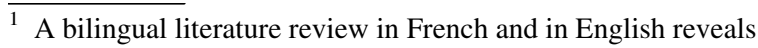
that only few references are common to both scientific communities.

2 In Canada, the provinces are in charge of implementing health policies under the auspices of federal and provincial legislation (e.g., the Canada Health Act 1984).
} 
intervention of the state in the system of health (Fleuret 2007).

To build understanding of the importance of networks in the development of new spaces of health and care, the first part of the paper examines the theoretical context. Specifically, what are the conceptual issues that underlie the set up of health networks? What are the arguments used, the issues faced? What are the characteristics of the French and Quebec cases? The second part of the paper presents the methodology based on qualitative interviews coupled together with a policy analysis of the functioning of the networks under investigation. Finally the findings reveal that, besides economic and health issues, spatial context and scale are essential issues.

\section{Theoretical context}

In France as in Quebec, authorities base their reforms on economic arguments. It is about rationalising the availability of services and structuring it in order to avoid duplication in order to save costs. One question to be answered in the future, however, is to know if these arguments are compatible with service ones relating to health and well-being (e.g., continuity of care, consistency professional practices for a better quality of service, liability, etc.). In policy discourses, the implementation of networks (for better integration) is considered as the solution that overcomes all the issues (Bailly et al. 2006). Thus, we accept that the principles underlying networking in health care move toward concerns of organization, economy and building of chains of care. The analytical structure of the undertaken research is based on the assumption that the restructuring that one can observe in local health systems to set up networks are a means to yield added value which are theoretically allotted to networking. Thus, the definition of new spaces of health care has to be seen as the result of a process of adjusting these theoretical values to the realities of a spatial context. This process is illustrated in Fig. 1. Health and organizational issues gravitate toward economic concerns. They can be assessed in terms of management toward changes in professional practices on the one hand, and interactions (at the scale of the community) for better access to care on the other hand. The changes in the branch of management relate to organizational issues. The changes in the branch of interactions relate to health issues. The novelty of this article is the attention paid to spatial restructuring versus integration process in this complex scheme.

Health issues: chains of care and epidemiological shift

Since the WHO has defined health as a state of complete physical, mental, and social well-being, not merely the absence of disease or infirmity (WHO, 1946), a "holistic" vision of health has become commonplace. It has logically led to the consideration of care more broadly than in a strict medical and hospital framework. Actions ensuing from that are, for example, opening hospitals in the city (breaking the barriers), coordinating the actors from the medical and social sectors in care delivery, and consultation and empowerment of the users. Yet, health care users can only make use of what is knowingly provided by actors from the medical and social sectors (this is a question of information) and of what is available in their everyday life spaces. If we consider that a patient must benefit from a package of primary care services, without discontinuity, a professional network must be organised from the upstream (prevention and promotion of health) to the downstream (post-curative care). Since care is not given in one single place like a hospital, but spread over a territory, the patient must be properly oriented in the system, in order to create a chain of care. This chain must be coherent in function of the successive interventions of caregivers (made necessary by his/ her condition), the nature of the given care, and the closely related services needed. Each individual and each actor in the system, therefore, have their own conception of the system, of their territory and of the resources that are the basis for the layout of personal routes within the health care system. This results in a sum of partial knowledge. The assumption is then one of a double "Do-it-yourself", from the patient and from the professionals.

The creation of coordinated chains of care thus requires three steps prior to implementation (Meyer and Coufinhal 1996; Bazzoli et al. 1999; Fleuret 2003, 2007). The first is an assessment of the needs for better access to care and services. Too often, the needs are assessed a posteriori, by measuring the 
Fig. 1 Conceptual framework of the principles underlying the restructuring in networks

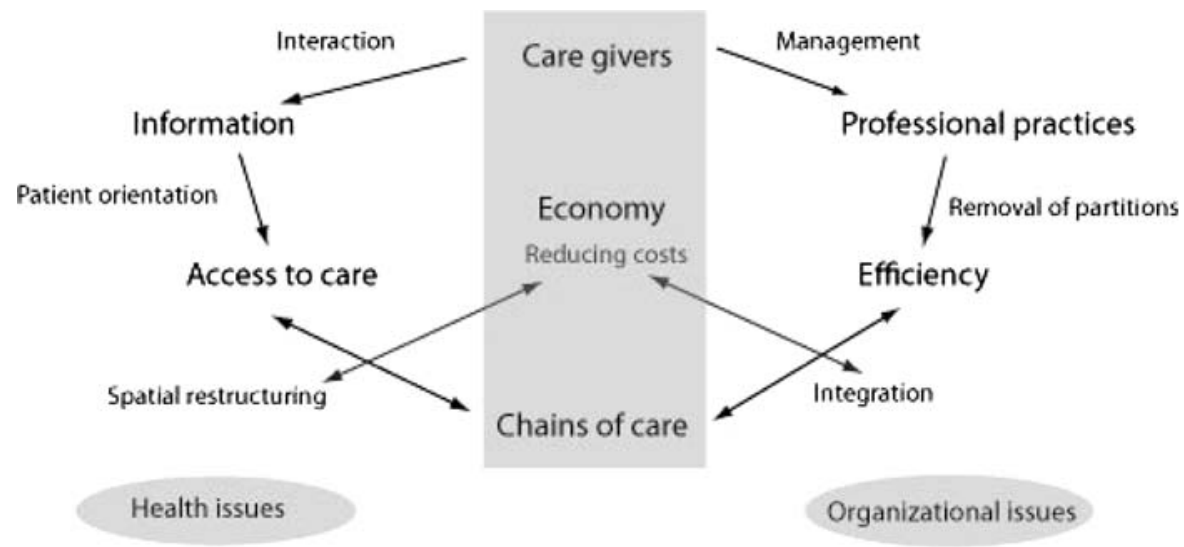

consumption of services. The second step is the removal of the partitions that compartmentalize the local systems of actors. The third preliminary step is the delineation of the territory of the network.

Recent evolutions are directly influencing the organisation of health systems and require an organisation into networks in order to supply chains of care. For Colvez et al. (2002, p. 25), "the most frequently used argument to justify the need for change in practices, within the health system, is the one of ageing. It is certain that this phenomenon has quantitative implications in the health system (more hospitalisations, more recourses to GP's), but in reality, the most important change is linked to an even more fundamental process which is the distribution of diseases within the population. This "epidemiological shift" has qualitative consequences on the practices of care giving which the professionals have not already assessed and which goes beyond the single issue of the number of elderly." Chronic diseases often come within the sphere of long-term care. The need is not only for treatment, but also for management and partnership (Jutras 1990), sometimes crossing the borders of the medical and social sectors (Meyer and Coufinhal 1996; Jaeger 2000) and this management has long-term implications in the everyday life of the patient. Thus, there is strong case for the coordination of professionals and the implementation of networks overlapping the medical and social sectors in delivering long-term care for those with chronic conditions. The process can be summed up by the search for a coherence of professional practices. A spatial coherence is also needed, at the local scale. Indeed, at this scale, professionals of health, social services, and stakeholders of the territory often do not know each other. Some of them (mostly non-profit organizations) are working in nearly invisible territories (Fleuret and Philibert 2006) and it would be illusory to hope to give coherence to the entire system before it is set up at the local scale.

Organizational issues: decompartmentalizing and restructurings

If professional practices are changing under the influence of health issues, organizational changes are also generating several issues. First, France and Quebec face a shortage of medical practitioners exacerbated by the spatial distribution of general practitioners (GPs) and resulting in difficulties in ensuring health care accessibility. This is partly the result of changes in professional practices. GPs today are less inclined to work alone (one can observe a rise in various forms of group practice). More women are working as GPs. Women GPs appear more often to choose part-time work and are more likely to practice in urban places and disregarding rural areas. In some remote areas in Quebec or in the central mountains in France, the situation is very problematic (Fleuret and Philibert 2006).

Second, in our two case studies, we face issues emanating from the continuity of health care delivery. Geographically, the issue is to insure that every patient can access a range of services within a reasonable perimeter around his or her home. Temporally, the issue is to guarantee an "on-call" service $24 \mathrm{~h}$ a day, 7 days a week. Networking is a response. It allows practitioners to share responsibilities, tasks, and tools. It noticeably modifies some professional habits and, at 
the same time, it favours the emergence of innovative practices (Meyer and Coufinhal 1996) which implies tight cooperation between each actors of a chain of care and a global decompartmentalizing of the practices and of the financing of services. For the moment, partitions exist especially in France between the social and medical sectors and these partitions correspond to different geographic scales, so we can also talk about a spatial compartmentalizing.

Building up networks is also one way to remedy (albeit with uneven results) increasing health expenditures and reducing spatial fragmentation. Since the 1980s, several Western countries have carried out territorial restructurings (Fleuret 2003) leading to mergers, groupings in order to externalise costs, and to save on overall costs. These restructuring strategies have mainly concerned the hospital sector (e.g., closing of departments) and have led to an ambulatory shift aiming at reducing hospitalisation stays and developing care "extra muros". For Bernier (2003, p. $53)$, the ambulatory shift "sought in principle to reduce costs by reducing the length of stay in institutions while improving basic and specialized home services provided by the health and social services networks." The consequence of the shift to home care is a substantial change in the scale of care delivery. For Cartier (2003, p. 2294), "[T]he main spatial transformation of health services provision has been the fragmentation ... by externalising certain kinds of services including non-medical or long term nursing care."

\section{The France and Quebec contexts}

The Anglo-American literature provides comprehensive coverage of the issues for the analysis of health networks but this literature is not well adapted to the French and Quebec contexts. France and Quebec afford new examples (Table 1) relating to different aims (e.g., in comparison to the US example) and, as pointed out already in relation to different spatial issues.

Moreover, despite very similar health policy contexts, in the case studies of France and Quebec, the spatial divisions of the health networks have two different forms resulting from recent restructurings.

In Quebec, the implementation of 95 local services networks resulted in all stakeholders located in a
Table 1 Types of networks

\begin{tabular}{lll}
\hline Type of network & Aims & $\begin{array}{c}\text { Localisation } \\
\text { (examples) }\end{array}$ \\
\hline $\begin{array}{l}\text { Managed care } \\
\begin{array}{c}\text { Integrated } \\
\text { network }\end{array}\end{array}$ & $\begin{array}{c}\text { Economic management } \\
\text { Spatial distribution of } \\
\text { services }\end{array}$ & USA \\
$\begin{array}{c}\text { Thematic } \\
\text { network }\end{array}$ & Professional coordination & France \\
\hline
\end{tabular}

given territory becoming responsible for the accessibility and continuity of services offered to their respective populations. New institutions known as health and social services centres were created at the heart of each local services network by merging local community health centres (CLSCs, from their French acronym), long-term care centres (CHSLDs, from their French acronym) and general and specialized hospital centres (CHSGSs, from their French acronym). This new type of institution was created by the Act respecting local health and social services network development agencies (Bill 25) in December 2004. According to this Act, each health and social services centre must develop service agreements with other partners in its local services network (i.e., medical clinics, family medicine groups, youth protection centres, rehabilitation centres, community organizations, university hospital centres, etc.) to provide all the services required by the population, including those it cannot itself provide. Thus, a network of services is created for each local territory. (Quebec Ministry of Health and Social Services, 2004).

In France, the situation is different. All the stakeholders remain autonomous. After an experiment with thematic networks was started in 1996, the law of March 4, 2002 on The Rights of the Patients and the Quality of the Care introduced a single and flexible definition of "health networks". The name "health networks" has been substituted for the former name "care networks" to allow for the inclusion of non-medical stakeholders. The definition of the networks of health specifies that the aim is to support the access to care, coordination, continuity, and interdisciplinarity. To reach this goal, the networks must: share best practices, thus be interdisciplinary and multi-professional; and be centred on the patient for whom they ensure a delivery of care adapted to 
Table 2 Interview protocol

\begin{tabular}{|c|c|c|}
\hline & $\begin{array}{l}\text { About the structuring } \\
\text { of the networks }\end{array}$ & $\begin{array}{l}\text { About the spatial issues } \\
\text { of the networks }\end{array}$ \\
\hline $\begin{array}{l}\text { Informations } \\
\text { to collect }\end{array}$ & $\begin{array}{l}\text { History of the network } \\
\text { Partnerships, stakeholders } \\
\text { Funding } \\
\text { Targets } \\
\text { Main accomplishments }\end{array}$ & $\begin{array}{l}\text { Territorial delineation } \\
\text { Geographical scales of reference (administration and funding) } \\
\text { Ability to localize partners and stakeholders } \\
\text { Localization of the main realizations }\end{array}$ \\
\hline Aims & To assess the level of integration & To assess the importance of space and place in the implementation of networks \\
\hline
\end{tabular}

his/her needs including health education, prevention, and diagnosis as care. The law also stipulates that the health networks contribute to the evolution of the system of health, which must be less partitioned and open to co-operation and complementarity between private and public hospitals, between GPs and other health professionals, and between various actors from different medical and social structures. Finally, a specific budget is created within the financing of social insurance but that relates only to medical expenditure. For the social insurance part, the networks must apply for other financing. Several networks have been created since 2002 in various places in France, but each one is different in terms of spatial coverage, speciality, medical concerns, and size. Every time spatial coordination and the removal of sectoral partitions are needed, a network is envisaged. For Philippe Chossegros (2005) president of the French National Coordination of Health Networks (CNR): "In reality, these networks are a response to the problems that the system of health does not want to solve". Others see in the networks a form of empowerment through the expression of local dynamics (discourse at the 4th congress of the CNR).

\section{Method}

The research was based on a mixed-methods approach including a literature review, policy analysis and analysis of interviews with key-informants. Triangulation of data from these sources was realized to assess integration and spatiality (Table 2).

First a review of the Francophone and international literature was undertaken, and complemented by a policy analysis of the legal texts in France and in
Quebec and by a qualitative study of 14 Local Services Networks (LSNs) in Quebec and 12 health networks in France. The results of this review provided data, which are used in the analysis to inform a comparison at the governmental level while the interviews provide results at the scale of the network organization and thus locally.

Following a phenomenological approach, ${ }^{3}$ the research aimed at studying the entire organization of these networks in the long-term. Investigations were conducted by using interviews. The questions were organized to set up a framework (Table 2) to ease the collection of information. Interviews were conducted over a period of 18 months with local stakeholders involved in the networks in 2005 and 2006. The people interviewed were chosen for their place and role in the networks. The sampling strategy used to identify and contact experts was different in France and Quebec.

In Quebec, the system is organized in networks. It is thus easy to identify the stakeholders and contact them. The panel of interviews was constructed in order to meet experts from networks located in three spatial categories: the metropolitan area (Montreal), the rural but not isolated area (Mauricie-Bois Francs and Eastern counties) and the remote areas (AbitibiTemiscamingue and Saguenay).

In France, networks are not present everywhere and are geographically scattered. It makes the

\footnotetext{
$\overline{3}$ Derived from Husserl's philosophy, the phenomenological approach consists in collecting information from the actors about a topic (e.g., restructurings in networks) as experienced from the first-person point of view.
} 
development of a sample more difficult than in Quebec. To avoid this difficulty, advantage was taken of a meeting organized in November 2005: the 4th Congress of the National Coordination for Health Networks (in Lille, France). All the interviews were conducted during this meeting.

The interviewees were either responsible for the coordination of the professionals in a network, responsible for the organization of services or both. Thus, the interviewed persons were administrators (mainly in Quebec), medical practitioners or nurses who have a global vision of the network to which they belong. Each interview was carried out face to face and lasted between 90 and $150 \mathrm{~min}$. Afterwards, the interviews were transcribed, not thoroughly, but in order to infill square by square the framework (interview protocol) presented in Table 2. The analytical framework for the research can be summed up in two dimensions: the structuring of the networks and spatial issues.

Lastly, textual material produced by the networks (commercials, management guidelines, strategic notes, manuals of good practices, etc.) was analysed in the same way (i.e., searching systematically for useful data to infill Table 2.

This methodology allowed for the collection of the points of view of the actors in the field and to place their information in perspective with the institutional discourse about the networks. Since the data were collected by using a mixed method, the results are also mixed in the analysis. When an interview is quoted, the name of the network is given in parentheses.

\section{Findings}

The real outcomes of health system restructuring and the implementation of networks in France and Quebec are essentially assessable in terms of changes in the structure of organizations. The findings arising from the comparison between France and Quebec are presented below in two parts. First, the results of the comparison at the scale of the global organizations show that a same goal (more integration and less fragmentation) produces different outcomes. Secondly, the findings at the scale of the networks show the importance of space in the restructurings of local health systems.
Contrast between a simple organization scheme (Quebec) and a complex one (France)

In Quebec, a single provincial ministry is responsible for health and social services while in France these two sectors are separated in two departments. In Quebec at the regional scale, one agency manages the whole of the system. It is a decentralized structure in that in each region there is one agency. In France, only hospital planning is regionalized. The socialmedical sector is managed at another spatial scale. ${ }^{4}$ In addition, these two scales are linked to the two separate departments mentioned above. It results in difficulties when, for example, cross-funding is required: "the processes of decisions remain too much partitioned in France" (Network Eollis). The differences in complexity of the organisational schemes between France and Quebec can also be observed from a geographical point of view. In Quebec, the entire territory is divided into 95 territories corresponding to local services networks. In France, the borders of the health networks vary according to the nature of the networks themselves. Some networks cover a broad area, bringing together all of the medical professionals in many places within the network (the biggest network of the studied panel accounted for 137 professionals) while others are centred on a single place (a municipality).

Yet, in both Quebec and France the main issue identified by the stakeholders is "to become conscious of its environment, of its social and cultural dimension" (CSSS Montreal). It is also one of the strongest arguments used to support reform in Quebec: to define territories fitting with the local reality. Thus, in the Canadian province, place and patient are emphasized as centres for the coordination of health professionals and health care planning (Quebec Ministry of Health and Social Services, 2004) whereas in France, networks are essentially centred on professionals. The spatial translation of this is that in Quebec, all the public local institutions have merged in one health and social services centre (forming the 95 local services networks). Consequently, one single service provider serves each local

\footnotetext{
4 The scale of the "département", not to be confused with the English word department that designate a government's divisions-the French "département" is akin to the county in Canada, the US and the UK.
} 
territory (Fig. 2). Moreover, all the stakeholders are brought together in the local services networks. In the French case, care and services delivery are based on the initiative of a group of professionals, locally organised, and taking on the management of the structure (National Coordination for Health Networks, France 2005). The professionals act as individual gatekeepers and regulate the first point of entry for the patient. The management of the system is under institutional responsibility.

In France, each stakeholder remains autonomous. Thus at a given place, one can find several thematic networks with little or no coordination. Amongst the case studies used for this research, one was a project of creating "une maison des réseaux de santé" (i.e., a common place for health networks). Four networks, legally four non-profit organisations (associations) were involved in this project. All the interviewees pointed out the same difficulties: first, defining a common framework in their everyday practices; second, the impossibility of merging, even partially because each partner wants to keep his specific activities and autonomy; and thirdly, difficulties related to funding. The French law suggests that a regional central fund for financing should be created in each of the 22 regions (the regional endowment for networks). In reality, this fund, however, "is relatively weak and do not always function effectively" (Network in Gerontology Sud Saumurois). Stakeholders have thus to "deal with many sources of funding" (Network Reseda) or at least one for medical issues, and one or more for social issues (because of the national division between the social and the medical sectors). However, such initiatives lead to pooling strategies. In the example presented above, a dietician, a social worker, a psychologist and a manager have joined together.

In Quebec, a result of the merger of local institutions is that financial management is centralized in the health and social services centres (under the control of regional agencies). "The main issue is thus the allocation of the resources to different areas of services" (CSSS Longueil). The hospital (especially emergency services) drains the biggest portion of the budget, which is worrying for those working in the preventive and primary care sectors, as they fear their mission might be swallowed up by this new structure dominated by medical services.

\section{Spatial concerns}

Findings at the spatial scale of the networks (i.e., locally) show that space really matters in different ways. The most frequent spatial concerns formulated in the discourses of the actors of the health networks are presented below organized following the structure presented in Table 2: localization and formalization of partnerships, scales of reference, and territorial delineations.

The originality of the French and Quebec models in comparison to more likely ones described in the international literature is the prevalence of public
Fig. 2 Actors in a local services network, Quebec. Source: Msss, Quebec

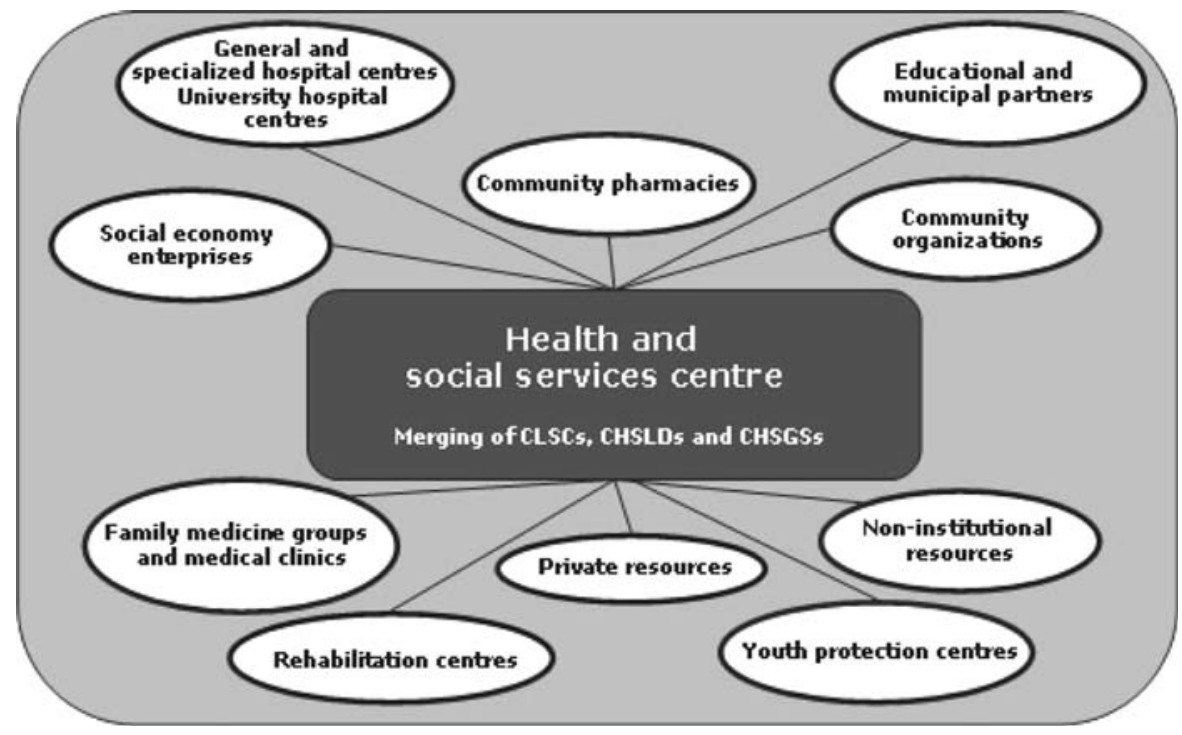


funding and a relative absence of private funding (Fleuret and Philibert 2006). Noticeably, the private insurance companies do not play the same role in France or Quebec, as in the USA (e.g., in terms of lobbying for the implementation of a managed care system).

In the relative absence of market forces, the territorial dimension is sometimes the only common denominator in both models. Whereas in theory, all the actors are supposed to work together, in practice, they are partitioned in professional or administrative sectors without any bridge provided between them. In France, we observe that the territorial stakeholders (e.g., municipal elected representatives) endorse the role of a leader "to give the first push towards more coordination" (Network Convergences). Afterwards, one observes different levels of joint actions, from the most elementary which consist only in sharing information, to the most complex setting up resources sharing, chains of care and detection (Table 3).

In Quebec, the government endorsed the role of a starter when proposing the reform which created the local health networks in 2003. Here, place primarily matters since the system, before restructuring, was already based on a spatialized offer of services intended to "meet the needs of the population on a given territory" (MSSS 2004). Place also mattered since the reform created new issues while merging some areas and so, generating spatial restructuring and more integration of services. The latter have become a cause for concern amongst some actors of the system, especially those of the community sector and those working in the field of health promotion. For them the issue arising is formulated as follow: "Will the integration process favour the biggest institutions (hospitals) to the detriment of the smallest

Table 3 Main activities of the networks (based on 12 networks in France)

Transmission of information among the actors of the network Training

Transmission of information outside the network

Assessment of patient needs

Sharing of material and means

Organization of a chain of care

Disease detection

In order of importance determined upon quoting frequency (community organizations)? And like a stone skimming, will it favour the emergency and specialized care at the detriment of the primary care and of the prevention?" (the director of a CLSC, Longueil, Quebec).

The spatial issues join up with the pecuniary ones. The territorial merger in Quebec also aims at achieving economies of scale in relation to a scarcity of resources. The federation of community organizations in Quebec is afraid of even more unevenness, which already exists, in the distribution of the means allocated to curative or preventive programs. This goes against one of the awaited benefit of network implementation: a global approach that favours prevention and promotion of health. This anxiety is all the more pronounced since the current tendency, in France and Quebec, is towards less intervention of the State. It has as a consequence, the transfer of many tasks to the community (decentralization) and often the corresponding means are not allocated (Network Eollis). Thus, we can observe a spatialized movement through decentralization and local devolution, which comes along with organizational changes and implies balancing and arbitration given that one attributes to the networks values of local liability.

On the basis of the statements collected during the interviews, Figs. 3 and 4 presented and discussed below illustrate two difficulties that the professionals have to face in the field. In Quebec, it is about issues raised by the resizing of the merged territories. Inversely, in France it is about "the seeking for a territorial coherence" (Eollis Network 2005) facing the imperfect overlapping of a multitude of administrative boundaries.

In Quebec, the systematic spatialization by merging all the local institutions in one, obviously offers advantages of liability, responsibility, and high level of integration. However, it also has disadvantages. The most important one is probably the question of the arbitrary nature of the geo-administrative divisions (i.e., territories or jurisdictions). To create the 95 local health networks, the government of Quebec merged 147 territories of local and community services centres. In several places, this change introduced significant modifications in the statistical profile of the population as shown on the maps of Montreal and Quebec City, two major urban centres in the province. The data mapped are the rate of 

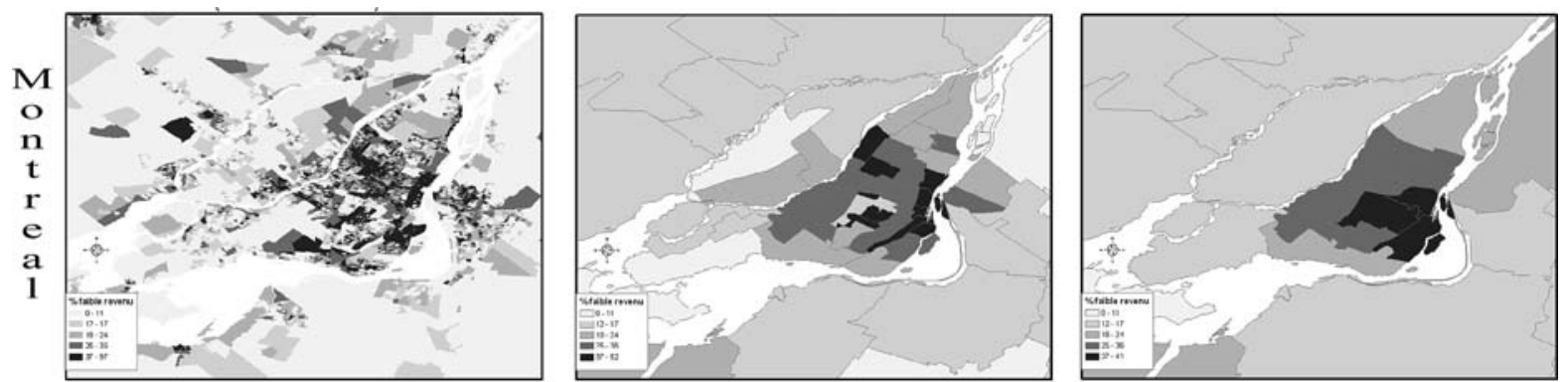

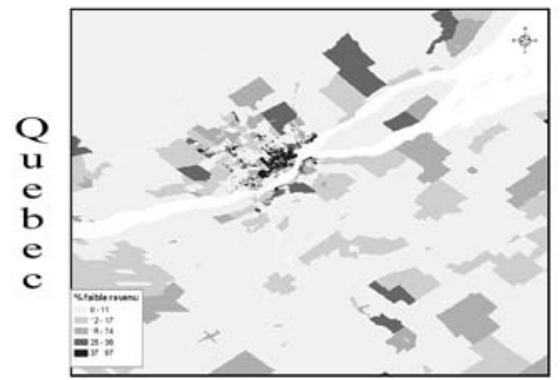

Census tracts

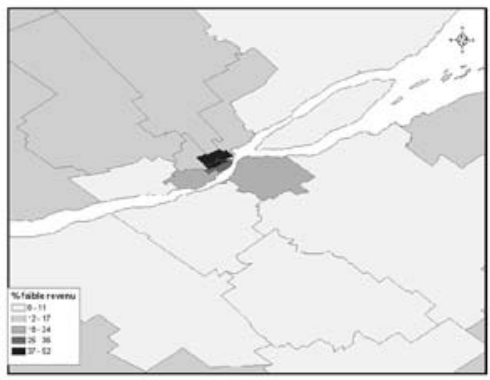

Local and community services centres

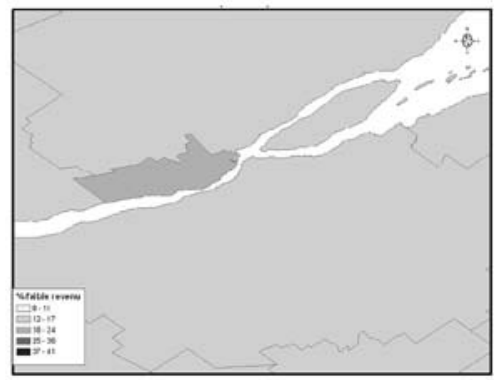

Local health networks

Fig. 3 Rate of households under low income thresholds at different scales (Montreal and Quebec city)

household under a low-income threshold. In Quebec City, especially, we can observe, at the scale of the local health networks, a complete smoothing of the disparities visible at the fine scale representation (i.e., low income cartographical threshold are the same at all scales).

Local organizations point out that particular attention is required to define the clinical planning of the local health networks so that the most deprived groups do not become invisible. Indeed, in this context, if there is a merger of all stakeholders in one single network, those small organizations are less heard. The changes in the social balance and the growth of the territory sizes induced by the merger have as a consequence a growing distance to care. For instance, in a health and social services centre, the person in charge of health promotion and community health noticed that the reform has led to a decreasing frequency of post-natal consultations. This is due to the expansion of the territory and to "a lowering of the spatial coherence in sociological terms" (a community worker, Montreal).

In France, health networks are producing new divisions. Instead of substituting the former divisions by the new ones, places are superimposed. The number of layers in the administrative geography introduces a complexity that becomes problematic. Figure 4 shows the number of scales that have to be accounted for in the management of a local network providing gerontology services. The stakeholders have to come to terms with: (i) the State; (ii) the region in charge of health planning; (iii) the Departments (counties) in charge of social financing; (iv) the divisions of health and proximity (local translations of regional planners); (v) the divisions produced by the networks, which are represented in Fig. 4 by the local coordination and information centres in gerontology (CLIC); and (vi) the municipalities, which intervene in territorial planning and for some social financing through the communal centres for social action. To set up a project, one has to coordinate numerous professionals whose places of reference are imperfectly and only partially overlapping. Furthermore, the local coordination areas do not cover all French territory.

All stakeholders agree that the future of health networks lies in research on territorial coherence. The current issues in health are such that the situation is moving rapidly. The recent regional plans for health organization have established divisions of health and proximity. These new spaces are coherent and relevant. It is now up to stakeholders to join by 


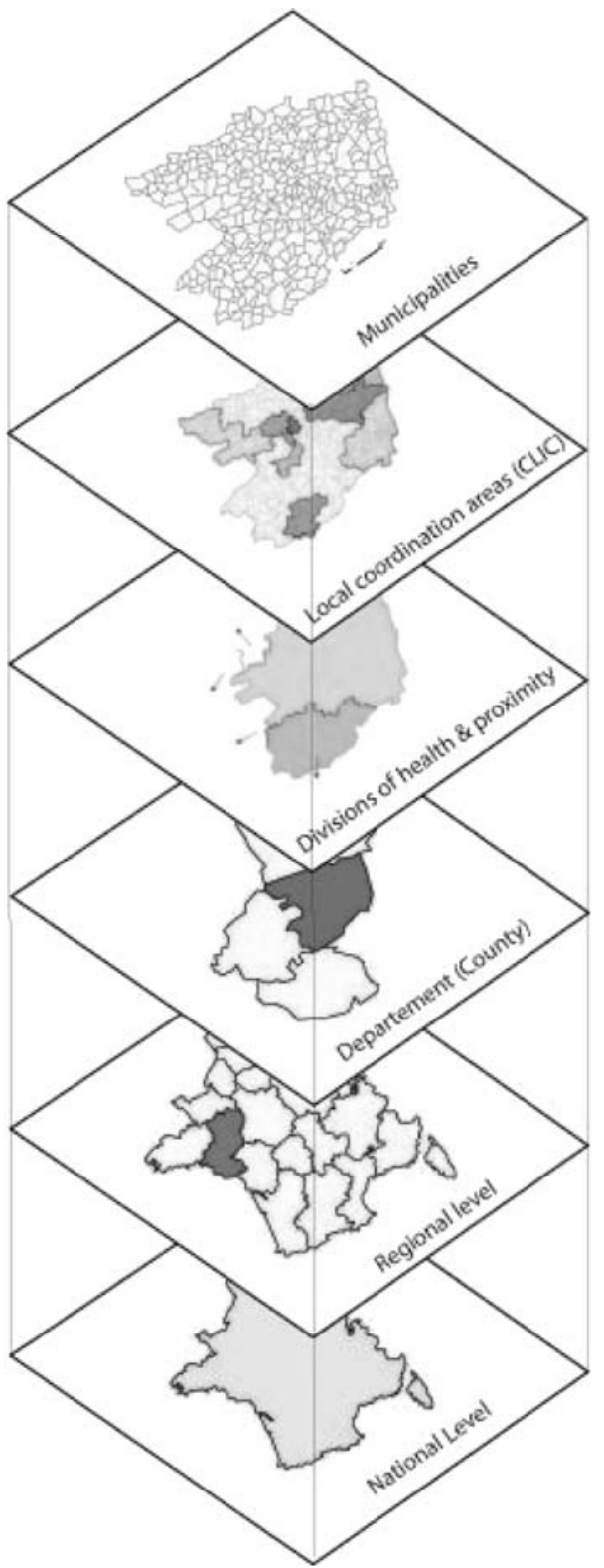

Fig. 4 Scales to come to terms with in order to set up a network in gerontology, in France (Maine \& Loire)

adapting the boundaries of their networks. However, the fact that the development of the networks is based on local initiatives is not the only disadvantage. In all the observed experiences, it appears that a major reason for the success of health care integration and the coordination service delivery is the implication of all professionals. In that way, the bottom-up development is an asset.

\section{Discussion}

The current trend toward restructuring health system results in gathering activities together. Attempts are made to compensate for this polarisation process by a spatial meshing in networks. It leads to new spaces of health. These spaces are places of bargaining and adjustments and confront policy makers with choices to make in the way to administer their territories.

France and Quebec provide examples in which the spatial issues are important in a context of limited intervention of the private sector-especially insurance companies-even if this situation could change in the future. ${ }^{5}$ Table 4 is a revised version of Table Two, in which specific spatial issues are related to localisation. The comparative analysis of France and Quebec is an invitation to pay more attention to geographic context in which the networks of health are implemented.

The French and Quebece case studies are particularly interesting because they offer the observer the results of two different options. In Quebec, the delineation of a territory is the founding decision of the networks. This foundation was translated into an act. The organization on the field is assigned to public structures, playing a fulcrum role. In France, the prerequisite to the implementation of a network is the definition of a professional framework for action. The spatial delineation is then negotiated between the actors and the stakeholders of each administrative scale of reference. The Quebec system offers the advantage of facilitating better interaction among actors and a better relationship between the caregivers and the community (it appears on the left branch of Fig. 1). The French system is more based on the activity of the professionals as well as on their capacity at adopting collective practices to provide services without discontinuities (i.e., see the right branch of Fig. 1). In both cases, the common point is research on spatial coherence, either in seeking for a better intra-territorial scale for action (Quebec) or in seeking for the best way to coordinate the caregivers in imperfectly overlapping spaces (France).

\footnotetext{
5 In the last few months, we observe, noticeably in France, that the insurance companies have propose managed care contracts to the health professionals. These companies seem to anticipate the fact that the state could take less responsibility for reimbursing care.
} 
Table 4 Types of networks and spatial issues

\begin{tabular}{llll}
\hline Type of network & Aims & Localisation (examples) & Spatial issues \\
\hline Managed care & Economic management & USA & Not primary \\
Integrated network & Spatial distribution of services & Quebec & Choices of scales and organisational coherence \\
Thematic network & Professional coordination & France & Territorial coherence \\
\hline
\end{tabular}

\section{Concluding comments}

Further extension of this research is, however, needed to address some limitations of this study. The existence of informal networks (that are wellresearched in the context of seniors care for instance) and their weak interactions with institutional actors is surely a first way to extend this research in the future.

The seeking for territorial and social coherence by setting up networks was quoted as a major issue in a great number of interviews. This issue should be assessed on a broader scale (e.g., in extension to other francophone jurisdictions).

Despite these limitations this study demonstrates that spatial context and scales are essential issues. While the economic and management issues lead to a greater polarisation, networks can be a way to keep the poles enmeshed and thus to avoid territorial discontinuities. Concerns are clearly identified by the actors in the field, and behind the notion of continuity of care, issues of spatial continuity are very strong. Thus, a major contribution of this article is to prove the utility to go one step further in the analysis of integration processes in the field of health care by adding a spatial dimension to an already complex scheme. Further research and also policy making should consider as a preamble the spatial delineation and the specification of the scales in the restructuring of local health systems in networks.

Finally, this study shows that it is restrictive to base a reflection on a single model. The cases studies of France and Quebec provide a new point of view. Thus, as well as an interdisciplinary approach, to understand all the issues, economic, health, spatial and political, an opening view on a greater variety of fields is welcome so new nuances can be explained and will improve the theoretical and global analysis of health systems.

Acknowledgments The author would like to thank Mark Skinner and Mark Rosenberg for their very helpful advises and corrections. This research was granted by the International council for Canadian studies and jointly by the Canadian institute of health research and the French national center for scientific research.

\section{References}

Ackerman, F. K. III. (1992). The movement toward vertically integrated regional health systems. Health Care Management Revue, 17(3), 81-88.

Ahgren, B., \& Axelsson, R. (2007). Determinants of integrated health care development: Chains of care in Sweden. International Journal of Health Planning and Management, 22(2), 145-157.

Ashton, T., Mays, N., \& Devlin, N. (2005). Continuity through change: The rhetoric and reality of health reform in New Zealand. Social Science \& Medicine, 61(2), 253-262.

Atkinson, S. (1995). Restructuring health care: Tracking the decentralization debate. Progress in Human Geography, 19(4), 486-503.

Bailly, A., Bernhardt, M., \& Gabella, M. (2006). Pour une santé de qualité en Suisse, $2^{\mathrm{e}}$ édition, Economica, $161 \mathrm{pp}$.

Bazzoli, G. J., Shortell, S. M., Dubbs, N., Chan, C., \& Kralovec, P. (1999). A taxonomy of health networks and systems: Bringing order out of chaos. Health Services Research, 33(6), 1683-1717.

Bernier, N. (2003). How health care reform impacts social policy and social redistribution. Canadian Review of Social Policy/Revue Canadienne de politique sociale, 52(fall/winter), 51-66.

Cartier, C. (2003). From home to hospital and back again: Economic restructuring, end of life, and the gendered problems of place-switching health services. Social Science \& Medicine, 56(11), 2289-2301.

Colvez, A., Gay, M., Blanchard, N., \& Fages, D. (2002). La Coordination Gérontologique. Pour qui, pourquoi, comment? Gérontologie et Société, 100, 25-34.

Conrad, D. A., \& Shortell, S. M. (1996). Integrated health systems: Promise and performance. Frontiers in Health Services Management, 13(1), 3-40.

Contandriopoulos, A.-P., Denis, J.-L., Touati, N., \& Rodriguez, C. (2001). Intégration des soins: Dimensions et mise en œuvre. Ruptures, revue transdisciplinaire en santé, 8(2), 38-52.

Eyles, J. (1990). How significant are the spatial configurations of health care systems? Social Science \& Medicine, 30(1), 157-164.

Ferlie, E. (1997). Large-scale organizational and managerial change in health care: A review of the literature. Journal of Health Services Research \& Policy, 2(3), 180-189. 
Fleuret, S. (2003). Recomposition du paysage sanitaire: Quand les exigences territoriales rejoignent les enjeux de santé. Revue Geocarrefour, 78(3), 239-246.

Fleuret, S. (2007). Organisation des systèmes, réseaux, coordination des services et des acteurs de la santé. In S. Fleuret \& J.-P. Thouez (Eds.), Géographie de la santé, un panorama (pp. 243-260). Editions EconomicaAnthropos.

Fleuret, S., \& Philibert, M. D. (2006). Réseaux locaux de services (RLS) au Québec: Les enjeux territoriaux d'une réforme. Espaces géographiques et société, travaux et documents de l'UMR 6590.

Fulop, N., Protopsaltis, G., King, A., Allen, P., Hutchings, A., \& Normand, C. (2005). Changing organisations: A study of the context and processes of mergers of health care providers in England. Social Science \& Medicine, 60(1), 119-130.

Iles, V., \& Sutherland, K. (2001). Organisational change: A review for health care managers, professionals and researchers. London: National Co-ordinating Centre for Service Delivery and Organisation. www.sdo.lshtm.ac.uk.

Jaeger, M. (2000). L'articulation du sanitaire et du social. Paris: Dunod. 170 p.

Jutras, S. (1990). Caring for the elderly: The partnership issue. Social Science and Medicine, 31(7), 763-771.

Kearns, R., \& Joseph, A. (1997). Restructuring health and rural communities in New Zealand. Progress in Human Geography, 21, 18-32.

Lamarche, P., Lamothe, L., Bégin, C., Léger, M., \& VallièresJoly, M. (2001). L'intégration des services: enjeux structurels et organisationnels ou humains et cliniques? Ruptures, revue transdisciplinaire en santé, 8(2), 71-92.

Lesser, C. S., Ginsburg, P., \& Devers, K. J. (2003). The end of an era: What became of the "managed care revolution. Health Services Research, 38(1 Pt 2), 337-355.
Meyer, C., \& Coufinhal, A. (1996) Partenariats, coordination, réseaux et filières dans le système de santé: le champ d'une décision politique ? Rapport pour le commissariat général du plan, SANESCO, $145 \mathrm{p}$.

Miller, D. L. (2000). Presentation on health policy economics. University of California, Irvine, Humanities Research Center (cit. in Cartier (2003). Social Science \& Medicine, 56(11), 2289-2301).

Moon, G. (1990). Conceptions of space and community in British health policy. Social Science \& Medicine, 30, 165-171.

Moscovice, I., Wellever, A., Christianson, J., Casey, M., Yawn, B., \& Hartley, D. (1997). Understanding integrated rural health networks. The Milbank Quarterly, 75(4), 563-588.

Nock, F. (2004). Et si l'on parlait de l'efficacité des réseaux. la santé de l'homme, 369, 19-21.

Robinson, J. C., \& Casalino, L. P. (1996). Vertical integration and organizational networks in health care. Health Affairs, 15(1), 7-22.

Shortell, S. M., \& Hull, K. E. (1996). The new organization of health care/managed care/integrated health systems. In S. Altman \& U. Reinhardt (Eds.), Strategic choices for a changing healthcare system (pp. 101-148). Chicago: Health Administration Press.

Smyth, F. (2005). Medical geography: Therapeutic places, spaces and networks. Progress in Human Geography, 29(4), 488-495.

Weil, T. P. (2000). Horizontal mergers in the United States health field: Some practical realities. Health Services Management Research, 13(30), 137-151.

WHO/OMS (groupe d'étude) (1996). Intégration de la prestation des soins de santé" in Série de rapports techniques, $\mathrm{n}^{\circ} 861,88 \mathrm{pp}$. 